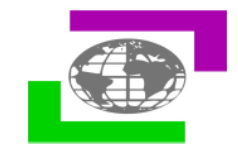

\title{
PREPARATION AND EVALUATION OF PARECOXIB MICROSPONGE HYDROGEL SUSTAINED RELEASED TABLET
}

Maruthi. N*, Lakshmi Radhika G

PG Department of Pharmaceutics, SJM College of Pharmacy, SJMIT Campus Chitradurga, India

Article Info: Received 14 May 2019; Accepted 14 June. 2019

DOI: https://doi.org/10.32553/jbpr.v8i3.615

Address for Correspondence: Maruthi. N, PG Department of Pharmaceutics, SJM College of Pharmacy, SJMIT Campus, NH4, Chitradurga- 577502, Karnataka, India.

Conflict of interest statement: No conflict of interest

\section{ABSTRACT:}

Microsponges are the polymeric drug delivery systems composed of porous microspheres. They are tiny sponge like spherical particles that consists of myriad of inter-connecting voids within a non-collapsible structure with a large porous surface. The present work is to formulate and evaluate the Parecoxib Microsponge Hydrogel Sustained Release Tablet. The Microsponges of Parecoxib is prepared by Quasiemulsion solvent diffusion method using Ethyl cellulose and Eudragit RS100 as polymers and Di-butyl phthalate as Plasticizer. And they are characterized for FTIR studies, production yield, particle size analysis, DSC and SEM. The production yields of formulations were from 77.77 to 82.75 . FTIR and DSC studies are revealed that the drug and polymer are compatible with each other during preparation. The average diameter of Microsponge is ranged from $536.9 \mathrm{~nm}$ to 489.7.

Parecoxib Microsponge hydrogel were prepared as sustained release tablets by using sustained release polymers like MCC, Magnesium stearate, Lactose and talc. Preformulation of Microsponge granules were carried out by various parameters and post formulation were carried out by In-vitro dissolution studies, hardness, friability and weight variation tests. Formulation F3 shows good results for the drug release kinetics as controlled release and F6 formulation shows good results for the in-vitro dissolution studies for sustained release.

Key words: Microsponge hydrogel drug delivery, Parecoxib, Sustained drug release tablets, quasi emulsion solvent diffusion method.

\section{INTRODUCTION}

The term "Drug Delivery" covers a very extensive range of techniques used to deliver therapeutic agents into the human body. Drugs are administered with a main aim of curing patient ailments. Drugs are never administered in their pure form but are converted in a suitable formulation so that its onset and intensity of action as well as total duration of action can be checked. Among the various routes of drug delivery oral route is most widely used route of drug delivery. But conventional dosage form offers few limitations which could be resolved by modifying the existing dosage form.

\section{Sustained Release Drug Delivery System:}

Among the various routes of drug delivery oral route is most preferred route. But conventional dosage form offers few limitations which could be resolved by modifying the existing dosage form. Sustained and controlled drug delivery system helps in constant plasma drug concentration and retards the release rate of drug thereby extending the duration of action. There are various formulation strategies for sustained release tablets among which diffusion system serves as an important tool.

Hence the problem like poor patient compliance, multiple dosing, and see-saw fluctuations can be 
easily minimized. They can be formulated by either direct compression or wet granulation method by using a variety of hydrophilic or hydrophobic polymers ${ }^{1}$.

\section{MATERIALS AND METHODS}

\section{Materials:}

Parecoxib was procured from Dr. J Timmasetty, HOD and Professor, Department of Pharmaceutics, Bapuji College of Pharmacy, Davanagere as gift sample, Ethyl cellulose and Di-butyl-phthalate was supplied from Loba Chemie Pvt. Ltd, Dichloromethane was supplied from S.D Fine chemicals Ltd, Mumbai, Eudragit RS 100 was supplies from Yarrow Chemicals Pvt. Ltd. And polyvinyl alcohol was supplied from Fisher Scientific India Pvt. Ltd.

Method:

Preparation of Parecoxib Microsponge by Quasi Emulsion Solvent Method:
Microsponges were prepared by quasi emulsion solvent diffusion method. Various concentrations of polymers (Eudragit RS 100 and Ethyl cellulose) and drug (Parecoxib) was dissolved in $20 \mathrm{ml}$ of Dichloromethane which acts as internal phase. The drug is dissolved under ultra-sonication at $350 \mathrm{C}$ for 15 minutes. Then weighed $1 \mathrm{gm}$ of PVA was dissolve in $180 \mathrm{ml}$ of water using water bath or magnetic stirrer not exceeding to $600 \mathrm{C}$ and pour remaining $20 \mathrm{ml}$ of water which acts as an external phase. Internal phase containing drug and polymer is poured to external phase (PVA and water), to this, add $1 \mathrm{ml}$ of Dibutyl Phthalate for the plasticity enhancement. Stirred the above solution using a propeller at $1200 \mathrm{rpm}$ for $2 \mathrm{hrs}$ at room temperature. Microsponges were settles at the bottom. The liquid is poured through Whattmen filter paper then the Microsponges were collected on the filter paper then dried at room temperature for $12 \mathrm{hrs}^{2}$.

Table 1: Composition of the prepared Parecoxib Microsponge hydrogel

\begin{tabular}{|l|l|l|l|l|l|l|l|}
\hline \multicolumn{2}{|l|}{ Internal Phase } & $\mathbf{F}_{1}$ & $\mathbf{F}_{\mathbf{2}}$ & $\mathbf{F}_{\mathbf{3}}$ & $\mathbf{F}_{\mathbf{4}}$ & $\mathbf{F}_{\mathbf{5}}$ & $\mathbf{F}_{\mathbf{6}}$ \\
\hline SI No & & & & & & & \\
\hline $\mathbf{1}$ & Parecoxib & $100 \mathrm{mg}$ & $100 \mathrm{mg}$ & $100 \mathrm{mg}$ & $100 \mathrm{mg}$ & $100 \mathrm{mg}$ & $100 \mathrm{mg}$ \\
\hline $\mathbf{2}$ & Eudragit RS 100 & $1.6 \mathrm{gm}$ & $1.7 \mathrm{gm}$ & $1.8 \mathrm{gm}$ & - & - & - \\
\hline $\mathbf{3}$ & Ethyl cellulose & - & - & - & $1.6 \mathrm{gm}$ & $1.7 \mathrm{gm}$ & $1.8 \mathrm{gm}$ \\
\hline $\mathbf{4}$ & Dichloromethane & $20 \mathrm{ml}$ & $20 \mathrm{ml}$ & $20 \mathrm{ml}$ & $20 \mathrm{ml}$ & $20 \mathrm{ml}$ & $20 \mathrm{ml}$ \\
\hline $\mathbf{5}$ & Dibutyl Phthalate & $1 \mathrm{ml}$ & $1 \mathrm{ml}$ & $1 \mathrm{ml}$ & $1 \mathrm{ml}$ & $1 \mathrm{ml}$ & $1 \mathrm{ml}$ \\
\hline External Phase & $1 \mathrm{gm}$ & $1 \mathrm{gm}$ & $1 \mathrm{gm}$ & $1 \mathrm{gm}$ & $1 \mathrm{gm}$ & $1 \mathrm{gm}$ \\
\hline $\mathbf{1}$ & PVA & $200 \mathrm{ml}$ & $200 \mathrm{ml}$ & $200 \mathrm{ml}$ & $200 \mathrm{ml}$ & $200 \mathrm{ml}$ & $200 \mathrm{ml}$ \\
\hline $\mathbf{2}$ & Water
\end{tabular}

\section{Characterization of Microsponges}

\section{Percentage Yield}

The prepared Microsponges of all batches were accurately weighed. The measured weight of prepared Microsponges was divided by total amount of all the excipients and drug used in the preparation of the Microsponges gives the total percentage yield of Microsponges. It was calculated by using following equation ${ }^{3}$.

Percentage yield $=\frac{\text { Actual weight of product }}{\text { Total weight of excepients and drug }} \times 100$

\section{Morphology study using SEM}

The morphological studies were carried out by ZEISS EVO. US Scanning Electron Microscope (SEM), connected with fine coat, JEOL JFC-1100E Ion sputter. The sample was loaded on copper sample holder and sputter coated with carbon followed by Gold ${ }^{4}$.

\section{Morphological study using DSC}

Differential scanning calorimetry (DSC) study was carried out to evaluate thermal behaviour and thermo tropic characteristics of the drug. Nearly 5 mg sample ( Parecoxib pure drug /ethyl cellulose 
/formulation F6) were sealed in aluminum pan followed by heating at a rate of $10^{\circ} \mathrm{C} / \mathrm{min}$ over temperature range of $40-300^{\circ} \mathrm{C}$ under nitrogen atmosphere of flow rate $10 \mathrm{ml} / \mathrm{min}$ and thermogram (Mettler-Toledo DSC 821e, Switzerland) was obtained $^{5}$.

\section{Particle size determination}

Particle size determination was done by Zeta potential analyser (Zetasizer) of Malvern Instruments Ltd. The instruments were designed to measure the size, shape and charge of particles. The average particle size was calculated as per the result.

\section{Drug content studies}

The weight equivalent to $100 \mathrm{mg}$ of drug was taken and transferred to a $100 \mathrm{ml}$ standard flask. $25 \mathrm{ml}$ of ethanol and $25 \mathrm{ml}$ of $7.4 \mathrm{pH}$ phosphate buffer were added and shaken for about half an hour and the volume was made up to $100 \mathrm{ml}$ with $7.4 \mathrm{pH}$ phosphate buffer. The above solution was filtered and $5 \mathrm{ml}$ of filtrate was taken and diluted to $100 \mathrm{ml}$ with $7.5 \mathrm{pH}$ phosphate buffer. The absorbance of the resulting solution was measured at $245 \mathrm{~nm}$ and the content of Parecoxib was calculated ${ }^{6}$.

\section{Evaluation of Parecoxib Microsponges}

\section{Determination of $\mathbf{p H}$}

Required quantity of prepared Microsponge was taken in suitable container and measured its $\mathrm{pH}$ by using digital $\mathrm{pH}$ meter. Microsponges were stable up to the $\mathrm{pH}$ range from 1 to $11^{7}$.

\section{Determination of viscosity ${ }^{8,9}$}

All formulated Microsponges were subjected to viscosity measurement by using a Brookfield digital viscometer (Analytical Technologies) by using spindle \#2 at room temperature. The measurement of consistency of the Microsponge hydrogel was done by dropping a cone attached to a holding rod from distance of $10 \mathrm{~cm}$ in such a way that, it should fall on centre of the glass cup filled with Microsponge. The distance travelled by the cone was measured.

\section{In vitro diffusion study ${ }^{10,11}$}

Cellophane membrane was used for this study in Frantz Diffusion Cell. 100mg of Microsponge is placed in donor compartment with which is filled phosphate buffer 7.4. The membrane was mounted between the compartments of the Frantz Diffusion Cell. Reservoir compartment was filled with phosphate buffer 7.4. The study was carried out at
$37 \pm 10$ and speed was adjusted to 100 to $120 \mathrm{rpm}$ and it is carried out for 24 hours. $5 \mathrm{ml}$ of sample was withdrawn from reservoir compartment by the help of hypodermic syringes at half an hour interval for 2 hours, then one hour interval for 10 hours and finally $6 \mathrm{hrs}$ to next $24 \mathrm{hrs}$. And absorbance was measured spectrophotometrically at $245 \mathrm{~nm}$. Each time the reservoir compartment was replenished with the $5 \mathrm{ml}$ fresh volume of phosphate buffer 7.4 $\mathrm{pH}$ solution to maintain constant volume.

\section{Preformulation parameters: Micromeritic properties}

\section{A. Bulk density and tapped $\backslash$ true density:}

Both bulk density (BD) and Tapped / True density were determined. Powder of Microsponge was taken in a $10 \mathrm{ml}$ measuring cylinder and initial volume was write and tapped at height of $2.5 \mathrm{~cm}$ at 2 -second intervals until no further change in volume was noted after tapping. BD and TD calculated using the following formula.

$$
\mathrm{BD}=\frac{\text { Weight of the powder }}{\text { volume of the powder }}
$$

$\mathrm{TD}=\frac{\text { Weight of the powder }}{\text { Tapped volume of the powder }}$

\section{B. Determination of carr's index:}

The compressibility index of the powder determined by the Carr's Compressibility index as shown in following formula

$$
\text { Carr's index }(\%)=\frac{\text { Tapped density-Bulk density }}{\text { Tapped density }} \times 100
$$

\section{Determination of the angle of repose:}

Angle of repose was measured for the Microsponge powder, to observe the flow properties of powders. The Funnel method was used; the powder was allowed to pass freely through a funnel and poured onto a horizontal plane, fixed base diameter, free of vibration petri dish to form a cone. The funnel height was maintained at approximately $2-4 \mathrm{~cm}$ from the tip of the powder pile in order to minimize the impact of the falling powder on the tip of the cone. The tan of angle of repose $(\theta)$ was calculated after measuring the height (h) of the cone of the powder. This follows following formula 
Maruthi. $\mathrm{N}$ et al., Journal of Biomedical and Pharmaceutical Research

Tan $\Theta=\frac{h}{r}$ where, $\mathbf{h}$ is the height of the pile in centimetre, $\mathbf{r}$ is the radius of the pile in centimetre

\section{Determination of hausner's ratio}

Hausner's ratio is a number that is correlated to the flow ability of a powder or granular material. The Hausner ratio is calculated by the formula where the freely settled bulk density of the powder, and the tapped density of the powder. A Hausner ratio greater than $\mathbf{1 . 2 5}$ is considered to be an indication of poor flowability. The formula is below mentioned ${ }^{12}$.

Hausner ratio $=\frac{\text { Tapped density }}{\text { bulk density }}$

Formulation of Parecoxib

Sustained Release Tablets

The formulated and evaluated Parecoxib Microsponges were prepared as Sustained Release tablets.

Table 2: Composition of Parecoxib sustained released tablets

\begin{tabular}{|l|l|l|l|l|l|}
\hline $\begin{array}{l}\text { Formulation } \\
\text { code }\end{array}$ & $\begin{array}{l}\text { Parecoxib Microsponges } \\
(\mathbf{m g})\end{array}$ & $\begin{array}{l}\text { Micro crystalline } \\
\text { cellulose }(\mathbf{m g})\end{array}$ & $\begin{array}{l}\text { Magnesium stearate } \\
(\mathbf{m g})\end{array}$ & $\begin{array}{l}\text { Talc } \\
(\mathbf{m g})\end{array}$ & $\begin{array}{l}\text { Lactose } \\
(\mathbf{m g})\end{array}$ \\
\hline F1 & 90 & 100 & 20 & 10 & 80 \\
\hline F2 & 92 & 100 & 20 & 10 & 78 \\
\hline F3 & 94 & 100 & 20 & 10 & 76 \\
\hline F4 & 92 & 100 & 20 & 10 & 78 \\
\hline F5 & 94 & 100 & 20 & 10 & 76 \\
\hline F6 & 96 & 100 & 20 & 10 & 74 \\
\hline
\end{tabular}

The Microsponge tablets were prepared as follows:

First weighed all the tablet ingredients according to the required formula. Then prepared $10 \%$ starch paste by adding starch to the $100 \mathrm{ml}$ water to 250 $\mathrm{ml}$ beaker and heat it until to get a smooth paste. Then blended the ingredients in mortar and pestle and add $100 \mathrm{mg}$ of previously prepared Microsponge hydrogel to above. Then add sufficient quantity of starch paste to above blended powders and finally damp mass is prepared. This prepared mass was passed through sieve no \#10 for the granules. This granule were dried under thermostatic ovens like tray drier until the moisture is completely removed. Then the dried granules were proceeded to further sieving (no \#22 and \#44) to make coarse and fines. Add $15 \%$ of fines to that of the total weight of coarse and finally add $2 \%$ of talc. The tablets were compressed into flat-faced punches of $10 \mathrm{~mm}$ diameter using Rimek Mini Press-I single sided rotary multiple station tablet compression machine.

Post formulation studies of Parecoxib loaded Microsponge tablets
Weight variation: 10 tablets are selected randomly and weighed individually and collectively and \% of weight variation is calculated by following formula.

$\%$ of weight variation $=\frac{\text { Individual Weight }- \text { Average weight }}{\text { Average Weight }} \times 100$

Hardness of tablet: The mechanical strength of the tablet was determined by using Monsanto hardness tester. This tester has a graduated scale which gives the reading in $\mathrm{Kg} / \mathrm{cm}^{2}$. The tablet to be tested was placed between the spindle and anvil. The desired pressure needed to hold the tablet in position is applied by moving the screw knob in clockwise direction. The scale was moved so that the indicator rested at zero. The pressure was applied till the tablet breaks. The reading were noted.

Thickness of tablet: Thickness of tablet is evaluated by using micrometre screw gauge. Test is carried out randomly on ten tablets and average values are calculated.

Friability: 10 tablets are weighed and placed in fribilator. The chamber is rotated for 4 minutes at a speed of 25 r.p.m. the tablets are removed from the chamber and weighed again. Loss in weight 
Maruthi. N et al., Journal of Biomedical and Pharmaceutical Research

indicates friability. The tablets to be considered of good quality if loss in weight is less than $0.8 \%$.

In vitro dissolution studies: In vitro dissolution study of tablets was performed using USP XXIV type II (type II) dissolution apparatus (3 $7 \pm 0.5,900$ $\mathrm{mL}, 50 \mathrm{rpm}$ ) in phosphate buffer $\mathrm{pH} 7.4$ for a period of $24 \mathrm{~h}$. Aliquots were taken out at every 1 hour interval for $24 \mathrm{~h}$, and the volume was replaced with an equivalent amount of aliquots of fresh dissolution medium. The samples were withdrawn and analysed spectrophotometrically at $245 \mathrm{~nm}$ respectively ${ }^{13}$.

\section{RESULTS AND DISCUSSIONS}

\section{UV spectrometric study}

This Parecoxib showed maximum absorption at wavelength $245 \mathrm{~nm}$ in phosphate buffer $\mathrm{pH}$ 7.4. The standard calibration curve obeys Beer's law and gives linear curve and the $R^{2}$ value is not greater than $0.999^{14}$.

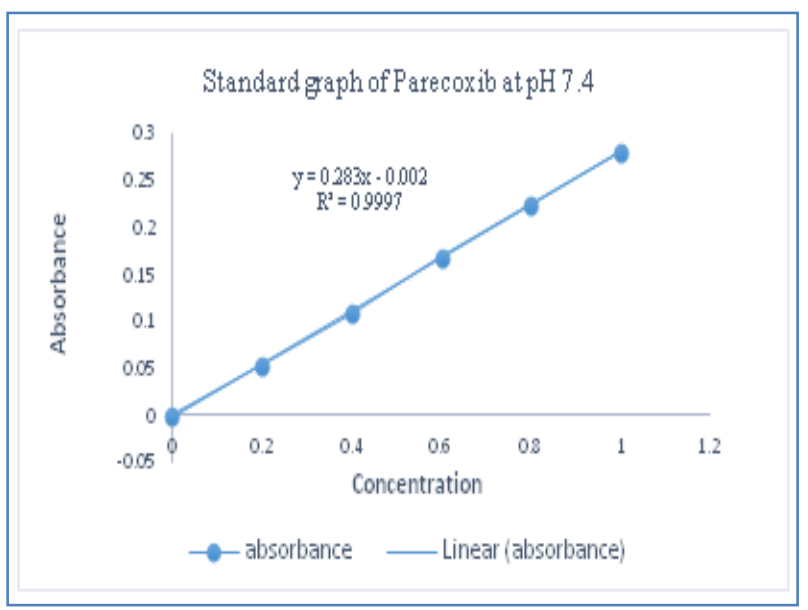

Figure 1: Calibration curve of Parecoxib in Phosphate buffer 7.4

\section{FTIR studies}

For the compatibility studies between drug and polymer selected are subjected to FTIR studies. IR spectrum of pure drug and polymer and physical mixture of drug and polymer (formulation) was recorded.

The IR spectra shows sharp peak at $3372 \mathrm{~cm}^{-1}$ due to presence of amine group $(\mathrm{NH})$ and it shows the peak at $1678 \mathrm{~cm}^{-1}$ due to the presence of $\mathrm{C}=\mathrm{O}$ groups corresponding to ketone groups. And presence of alkenes $(C=C)$, the spectra shows peak at $1618 \mathrm{~cm}^{-1}$. These similar peaks are obtained in formulation also. It indicates that the pure drug functional groups peaks were present in all the formulations without changes in the peaks position 15 .

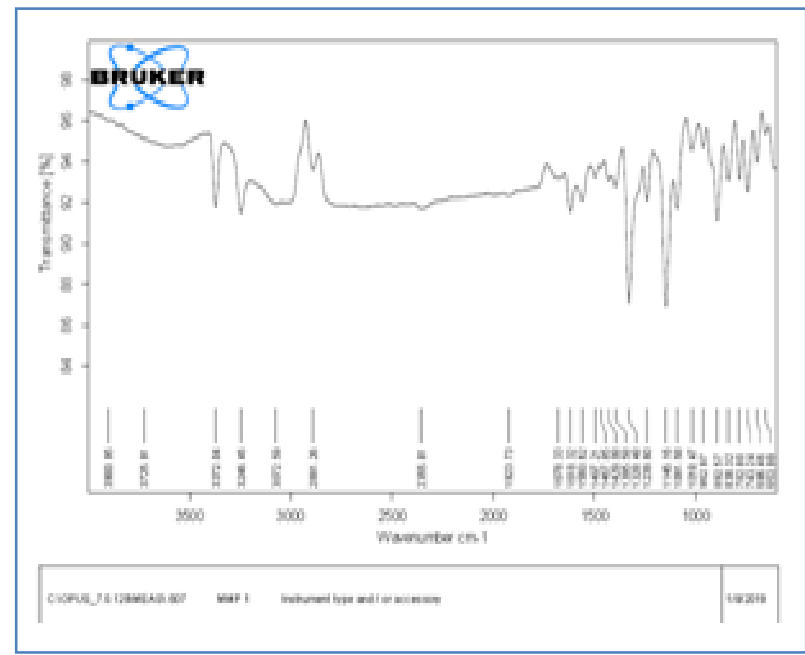

Figure 2: IR spectra of Pure Parecoxib Drug

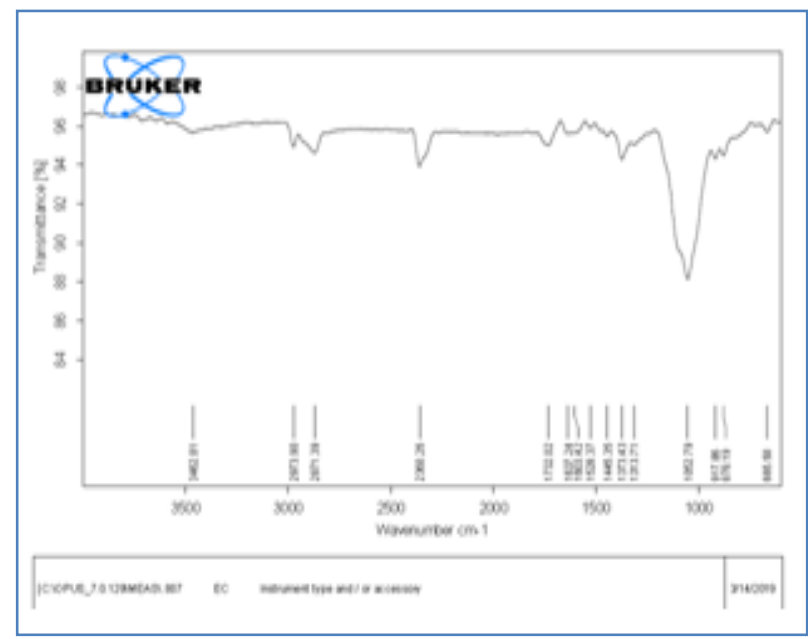

Figure 3: IR spectra of Ethyl cellulose

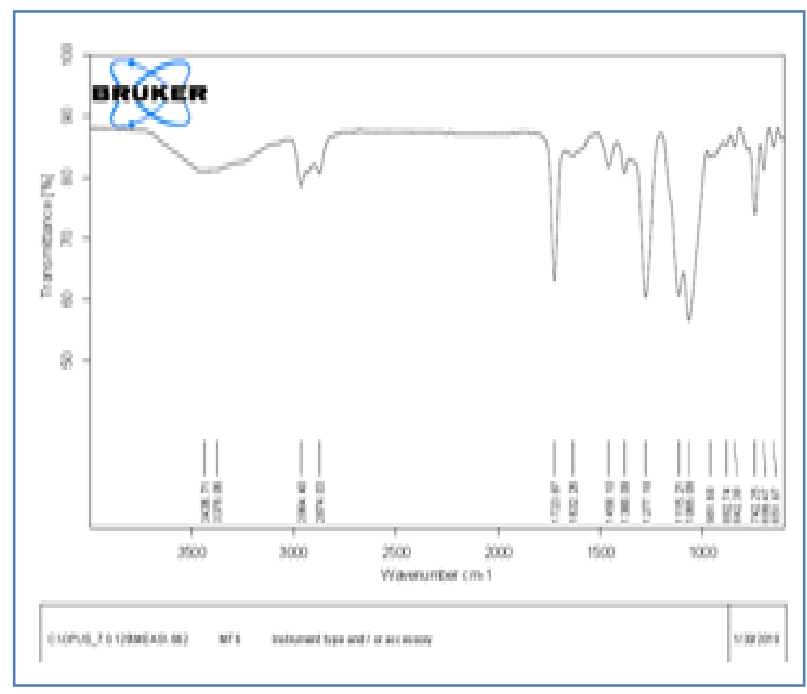

Figure 4: IR spectra of Microsponge formulation $F_{6}$ 


\section{SEM studies}

The SEM images of formulation F3 and F6 reveals that the microsponges were highly porous in nature and pore size is less than $1 \mu$ with discrete spherical and smooth in surface.

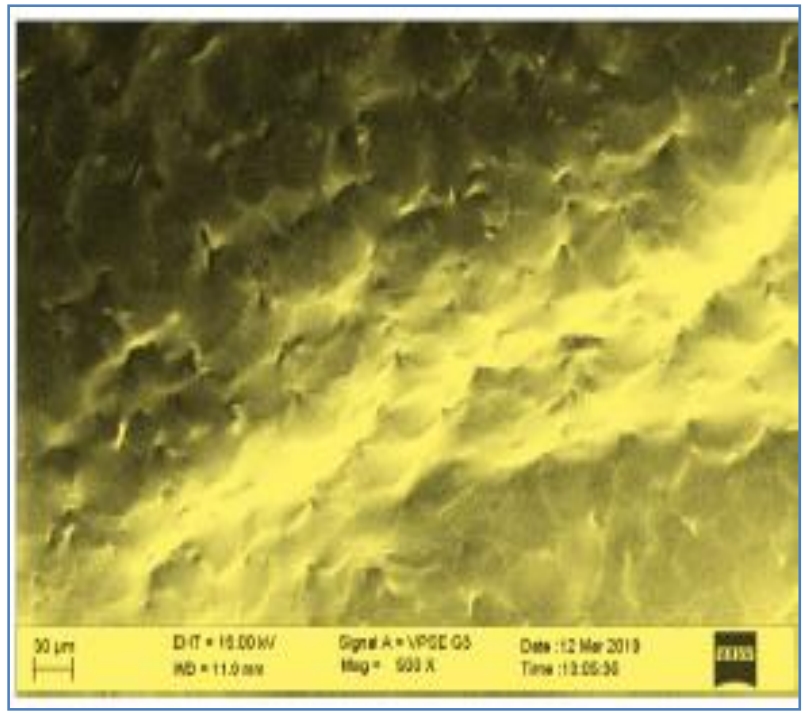

(A)

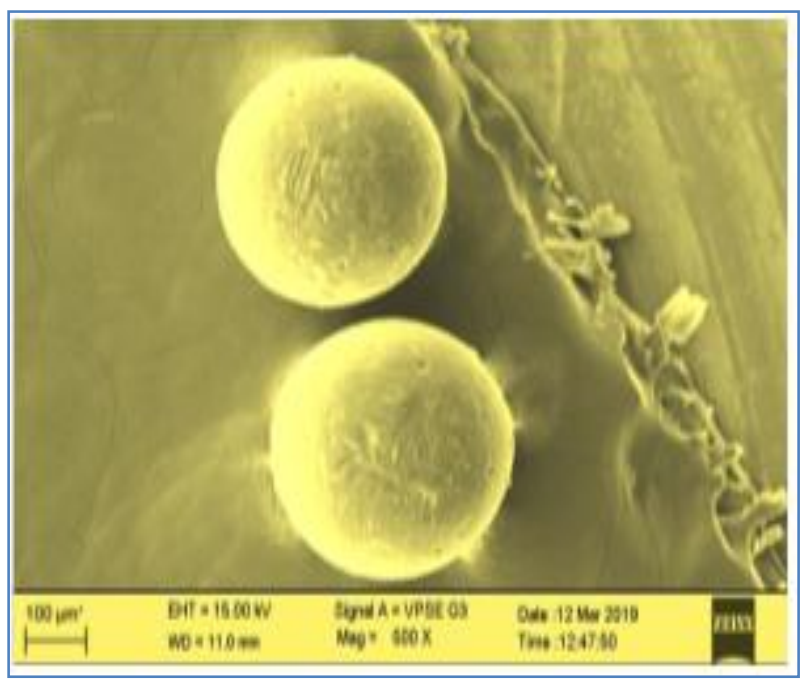

(B)

Figure 5: Highly porous nature (A) and spherical nature $(B)$ of Microsponges

\section{Particle size analysis}

The particle size determination of Microsponge formulation was carried out by particle size analyser (Zetasizer, Malvern) and recorded. The average diameter of the Microsponges was found to be $536 \mathrm{~nm}$ to $412 \mathrm{~nm}$. Particle size of
Microsponges was increased on increasing in the polymer content and they were mention in Table No. 3

\section{Drug content studies}

The drug content study of all Microsponge formulations was carried out by suitable method as mentioned in above methodology. The \% drug content was in the range of $\mathbf{8 2 . 1 6}$ to $\mathbf{9 2 . 1 5} \%$. The F6 formulation shows highest drug content compare to other formulation. Different concentrations of two different polymers may changes the drug content. And they are fairly exhibited uniform drug content. The values are shown Table No. 3

\section{DSC studies}

DSC thermograms of plain Parecoxib and Microsponges without drug and drug loaded Microsponges was recorded. Drug without Microsponges have shown an endothermic peak at 104.340 C, whereas Parecoxib loaded Microsponges shows a peak at $103.190 \mathrm{C}$ and 115.540 C. The plain Parecoxib has showed an endothermic peaks at $172.360 \mathrm{C}$ due to the melting of drug. But this peak is not exactly seen in drug loaded formulations. This indicates the drug was amorphously or uniformly distributed in amorphous forms in formulations.

\section{pH studies}

The $\mathrm{pH}$ of all six formulations were performed by $\mathrm{pH}$ meter and it shown in the $\mathrm{pH}$ range of $\mathbf{6 . 2}$ to 6.9 as shown in Table no 3. The formulation F6 shows highest $\mathrm{pH}$ compare to other formulation. By changing different polymers in different concentration in the formulation may lead to changes in the $\mathrm{pH}$ of the preparation.

\section{Viscosity studies}

It was performed for all six Microsponge formulations. The viscosity is in the range of $\mathbf{2 1 3 8}$ to 2497 cps. Formulation F6 shows highest viscosity range. These were free flowing in nature and optimum range. The values are mention in Table No. 3 
Maruthi. N et al., Journal of Biomedical and Pharmaceutical Research

Table 3: Drug content, particle size analysis, $\mathrm{pH}$ and viscosity of Microsponge formulation

\begin{tabular}{|l|l|l|l|l|l|}
\hline SI No & Formulation code & Drug content & Particle size analysis $(\mathbf{n m})$ & pH & Viscosity \\
\hline 1 & $\mathrm{~F}_{1}$ & $82.16 \%$ & 530 & 6.2 & $2355 \mathrm{cps}$ \\
\hline 2 & $\mathrm{~F}_{2}$ & $86.72 \%$ & 520 & 6.3 & $2364 \mathrm{cps}$ \\
\hline 3 & $\mathrm{~F}_{3}$ & $90.40 \%$ & 536 & 6.5 & $2165 \mathrm{cps}$ \\
\hline 4 & $\mathrm{~F}_{4}$ & $85.13 \%$ & 412 & 6.6 & $2255 \mathrm{cps}$ \\
\hline 5 & $\mathrm{~F}_{5}$ & $89.24 \%$ & 489 & 6.2 & $2138 \mathrm{cps}$ \\
\hline 6 & $\mathrm{~F}_{6}$ & $92.15 \%$ & 432 & 6.9 & $2497 \mathrm{cps}$ \\
\hline
\end{tabular}

\section{Diffusion studies}

The in vitro diffusion studies of Microsponge formulations were carried out by using Franz's diffusion cell and using cellophane membrane as barrier. The results of in vitro diffusion studies are shown in Table no 4. The cumulative percentage of drug diffusion from F1 to F6 ranges from $70.65 \%$ to $90.63 \%$. Formulation ' $F 3$ ' shows second highest percentage drug release (89.2306) and from the graph it shows the drug release in 'controlled manner' compare to other formulations. The release kinetics was evaluated by making use of Zero order, First order, Higuchi's diffusion and Peppas equation.
The drug release through the Microsponge hydrogel of Parecoxib follows Peppas diffusion kinetics with controlled mechanism and the ' $n$ ' values are in between 0.51 to 0.7 . By fitting in the Korsemeyer- Peppas equation the release kinetics follows non Fickian kinetics. If the ' $n$ ' values of Korsemeyer- Peppas equation below 0.5, this indicates Fickian kinetics. If the ' $n$ ' values of Korsemeyer- Peppas equation is in between 0.5 to 1 , this indicates non-Fickian kinetics. Here the Microsponges of Parecoxib release kinetics are fitted in Korsemeyer- Peppas equation. ' $n$ ' values are in between 0.5 to 1 , so the release is following non Fickian, diffusion controlled kinetics. The regression co-efficient values are given in Table $\mathbf{5}$

Table 4: In-vitro drug release kinetics of Microsponge formulation $F_{1}$ to $F_{6}$

\begin{tabular}{|c|c|c|c|c|c|c|}
\hline \multirow{3}{*}{$\begin{array}{l}\text { Time } \\
\text { (hr) }\end{array}$} & \multicolumn{6}{|c|}{ \% Drug Release * } \\
\hline & \multicolumn{6}{|c|}{$\overline{\mathbf{X}} \pm$ SD } \\
\hline & $F_{1}$ & $F_{2}$ & $F_{3}$ & $F_{4}$ & $F_{5}$ & $F_{6}$ \\
\hline 0 & 0 & 0 & 0 & 0 & 0 & 0 \\
\hline 0.5 & $7.32 \pm 0.015$ & $13.01 \pm 0.020$ & $16.23 \pm 0.041$ & $10.62 \pm 0.035$ & $18.03 \pm 0.020$ & $6.23 \pm 0.025$ \\
\hline 1 & $12.03 \pm 0.020$ & $18.33 \pm 0.015$ & $24.57 \pm 0.035$ & $16.02 \pm 0.020$ & $26.13 \pm 0.036$ & $13.56 \pm 0.021$ \\
\hline 1.5 & $16.22 \pm 0.017$ & $23.56 \pm 0$ & $28.63 \pm 0.036$ & $26.68 \pm 0.036$ & $36.56 \pm 0.040$ & $19.23 \pm 0.017$ \\
\hline 2 & $23.60 \pm 0.025$ & $27.62 \pm 0.020$ & $33.63 \pm 0.036$ & $32.56 \pm 0.036$ & $48.26 \pm 0.036$ & $26.15 \pm 0.022$ \\
\hline 3 & $27.96 \pm 0.025$ & $39.52 \pm 0.025$ & $39.67 \pm 0.026$ & $37.06 \pm 0.026$ & $53.15 \pm 0.004$ & $28.23 \pm 0.040$ \\
\hline 4 & $31.67 \pm 0.021$ & $47.24 \pm 0.020$ & $48.95 \pm 0.036$ & $45.36 \pm 0.040$ & $65.23 \pm 0.045$ & $32.65 \pm 0.035$ \\
\hline 5 & $45.59 \pm 0.026$ & $55.80 \pm 0.030$ & $56.63 \pm 0.030$ & $50.25 \pm 0.035$ & $71.96 \pm 0.020$ & $36.58 \pm 0.045$ \\
\hline 6 & $54.65 \pm 0.026$ & $62.64 \pm 0.030$ & $67.05 \pm 0.040$ & $62.29 \pm 0.040$ & $82.13 \pm 0.036$ & $41.06 \pm 0.026$ \\
\hline 7 & $65.34 \pm 0.021$ & $77.65 \pm 0.020$ & $79.34 \pm 0.030$ & $69.32 \pm 0.040$ & $80.26 \pm 0.022$ & $52.68 \pm 0.030$ \\
\hline 8 & $72.61 \pm 0.00$ & $78.89 \pm 0.026$ & $82.61 \pm 0.026$ & $75.68 \pm 0.040$ & $80.63 \pm 0.017$ & $56.12 \pm 0.036$ \\
\hline 9 & $80.35 \pm 0.017$ & $84.74 \pm 0.036$ & $85.60 \pm 0.050$ & $78.26 \pm 0.030$ & $78.23 \pm 0.026$ & $62.12 \pm 0.035$ \\
\hline 10 & $83.65 \pm 0.030$ & $82.35 \pm 0.036$ & $86.35 \pm 0.045$ & $84.26 \pm 0.036$ & $85.13 \pm 0025$ & $68.63 \pm 0.017$ \\
\hline 11 & $85.25 \pm 0.026$ & $83.26 \pm 0.022$ & $87.61 \pm 0.036$ & $80.35 \pm 0.030$ & $82.56 \pm 0.017$ & $70.62 \pm 0.015$ \\
\hline 12 & $85.95 \pm 0.026$ & $85.25 \pm 0.040$ & $89.23 \pm 0.035$ & $78.26 \pm 0.004$ & $86.26 \pm 0.015$ & $72.01 \pm 0.036$ \\
\hline 18 & $84.25 \pm 0.030$ & $89.26 \pm 0.030$ & $87.25 \pm 0.036$ & $83.16 \pm 0.045$ & $85.52 \pm 0.030$ & $75.26 \pm 0.004$ \\
\hline 24 & $82.65 \pm 0.020$ & $90.63 \pm 0.025$ & $86.64 \pm 0.026$ & $70.65 \pm 0.053$ & $78.26 \pm 0.026$ & $79.26 \pm 0.030$ \\
\hline
\end{tabular}


Maruthi. $\mathrm{N}$ et al., Journal of Biomedical and Pharmaceutical Research

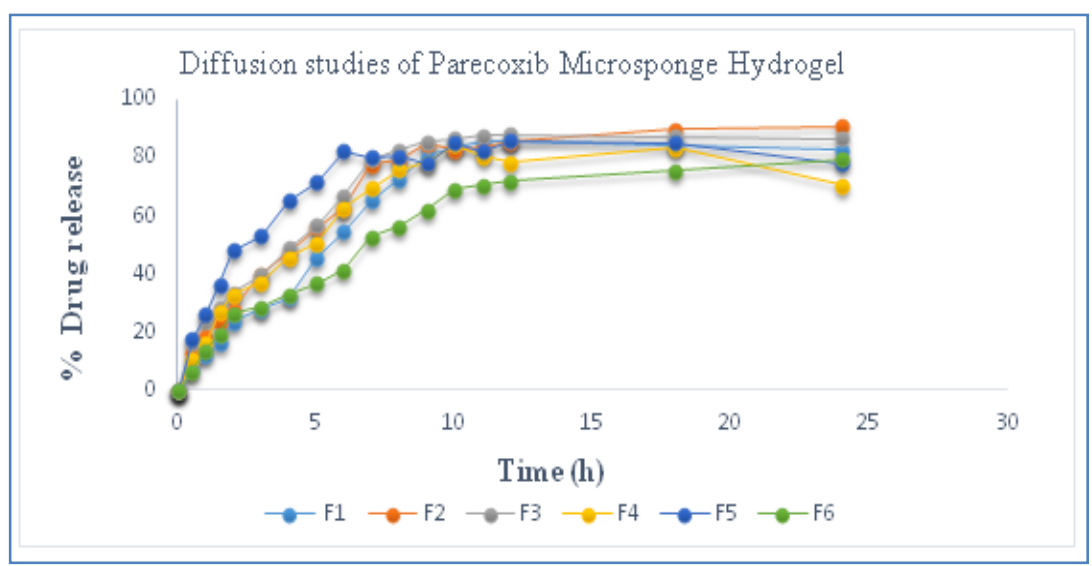

Figure 6: Graph of in vitro drug release of Microsponge formulation $F_{1}$ to $F_{6}$

Table 5: Regression co-efficient $\left(R^{2}\right)$ values of Parecoxib Microsponge hydrogel according to different kinetic models

\begin{tabular}{|l|l|l|l|l|l|l|l|}
\hline \multirow{2}{*}{ Formulation } & \multicolumn{2}{|l|}{ Zero order } & \multicolumn{2}{l|}{ First order } & Higuchi & \multicolumn{2}{l|}{ Peppas } \\
\cline { 7 - 8 } & $\mathbf{R}^{\mathbf{2}}$ & $\mathbf{n}$ & $\mathbf{R}^{\mathbf{2}}$ & $\mathbf{n}$ & $\mathbf{R}^{\mathbf{2}}$ & $\mathbf{R}^{\mathbf{2}}$ & $\mathbf{n}$ \\
\hline $\mathrm{F}_{1}$ & 0.6780 & 3.8896 & 0.7105 & 0.096 & 0.8557 & 0.9185 & 0.7032 \\
\hline $\mathrm{F}_{2}$ & 0.6792 & 3.7541 & 0.8390 & 0.111 & 0.8864 & 0.9257 & 0.5662 \\
\hline $\mathrm{F}_{3}$ & 0.6196 & 3.4856 & 0.6928 & 0.101 & 0.8499 & 0.9098 & 0.5398 \\
\hline $\mathrm{F}_{4}$ & 0.5601 & 3.0688 & 0.5620 & 0.071 & 0.8019 & 0.8691 & 0.5134 \\
\hline $\mathrm{F}_{5}$ & 0.4578 & 2.6588 & 0.5182 & 0.071 & 0.7430 & 0.8084 & 0.5652 \\
\hline $\mathrm{F}_{6}$ & 0.7927 & 3.3755 & 0.8896 & 0.072 & 0.9374 & 0.9577 & 0.5890 \\
\hline
\end{tabular}

\section{Pre formulation studies of Parecoxib loaded Microsponge tablets}

The blended granules with Microsponges were subjected to various preformulation studies like true density, bulk density, angle of repose, carr's index and finally hausner's ratio. The results were mentioned in Table no. 6. All preformulation studies shows that excellent flow property and they are in within the IP limits.

Table 6: Micromeritic properties of Microsponge hydrogel with granules

\begin{tabular}{|l|l|l|l|l|l|}
\hline Blends & $\begin{array}{l}\text { True density } \\
(\mathbf{g m} / \mathbf{m l}) * \overline{\mathbf{X}} \pm \text { SD }\end{array}$ & $\begin{array}{l}\text { Bulk density }(\mathbf{g m} / \mathbf{m l}) * \\
\overline{\mathbf{X}} \pm \text { SD }\end{array}$ & $\begin{array}{l}\text { Angle of repose * } \\
\overline{\mathbf{X}} \pm \text { SD }\end{array}$ & $\begin{array}{l}\text { Carr's index (\%)* } \\
\overline{\mathbf{X}} \pm \text { SD }\end{array}$ & $\begin{array}{l}\text { Hausner's ratio * } \\
\overline{\mathbf{X}} \pm \text { SD }\end{array}$ \\
\hline $\mathbf{F}_{\mathbf{1}}$ & $0.475 \pm 0.023$ & $0.44 \pm 0.017$ & $25.6^{\circ} \pm 0.001$ & $7.53 \pm 0.015$ & $1.08 \pm 0.050$ \\
\hline $\mathbf{F}_{\mathbf{2}}$ & $0.494 \pm 0.026$ & $0.46 \pm 0.036$ & $26.5^{\circ} \pm 0$ & $8.32 \pm 0.026$ & $1.04 \pm 0.026$ \\
\hline $\mathbf{F}_{\mathbf{3}}$ & $0.473 \pm 0.031$ & $0.44 \pm 0.023$ & $26.6^{\circ} \pm 0.007$ & $4.25 \pm 0.036$ & $1.04 \pm 0.021$ \\
\hline $\mathbf{F}_{\mathbf{4}}$ & $0.515 \pm 0.023$ & $0.45 \pm 0.021$ & $24.7^{\circ} \pm 0.001$ & $5.76 \pm 0.021$ & $1.06 \pm 0.007$ \\
\hline $\mathbf{F}_{\mathbf{5}}$ & $0.507 \pm 0.050$ & $0.45 \pm 0.021$ & $25.6^{\circ} \pm 0.005$ & $5.32 \pm 0.023$ & $1.04 \pm 0.017$ \\
\hline $\mathbf{F}_{\mathbf{6}}$ & $0.564 \pm 0.036$ & $0.53 \pm 0.026$ & $24.2^{\circ} \pm 0.007$ & $6.19 \pm 0.026$ & $1.06 \pm 0.026$ \\
\hline
\end{tabular}

* mean of 3 readings

Post formulation studies of Parecoxib loaded Microsponge hydrogel sustained release tablets

The formulated Microsponge sustained released tablets were subjected to various post formulation parameters like weight variation, hardness test, friability, diameter and thickness and the results are mentioned in Table no. 7. The In vitro Dissolution studies were also performed for the sustained release tablets. All the formulations were in IP limits. 
Maruthi. N et al., Journal of Biomedical and Pharmaceutical Research

Table 7: Weight Variation, Hardness, Friability, Diameter and Thickness of Parecoxib loaded Microsponge sustained released tablets

\begin{tabular}{|l|l|l|l|l|l|}
\hline $\begin{array}{l}\text { Formulation } \\
\text { Code }\end{array}$ & $\begin{array}{l}\text { \% weight } \\
\text { variation }\end{array}$ & $\begin{array}{l}\text { Hardness test } \\
\left(\mathbf{k g} / \mathbf{c m}^{2}\right)\end{array}$ & Friability $\mathbf{( \% )}$ & $\begin{array}{l}\text { Diameter } \\
(\mathbf{m m})\end{array}$ & $\begin{array}{l}\text { Thickness } \\
(\mathbf{m m})\end{array}$ \\
\hline $\mathbf{F}_{\mathbf{1}}$ & $2.57 \pm 0.026$ & $4.52 \pm 0.025$ & $0.466 \pm 0.036$ & $8.13 \pm 0.022$ & $4.026 \pm 0.030$ \\
\hline $\mathbf{F}_{\mathbf{2}}$ & $3.56 \pm 0.030$ & $4.84 \pm 0.030$ & $0.360 \pm 0.044$ & $8.15 \pm 0.040$ & $4.025 \pm 0.022$ \\
\hline $\mathbf{F}_{\mathbf{3}}$ & $2.27 \pm 0.044$ & $4.72 \pm 0.025$ & $0.498 \pm 0.022$ & $7.97 \pm 0.036$ & $4.031 \pm 0.028$ \\
\hline $\mathbf{F}_{\mathbf{4}}$ & $2.93 \pm 0.025$ & $4.82 \pm 0.025$ & $0.380 \pm 0.036$ & $8.16 \pm 0.025$ & $4.015 \pm 0.025$ \\
\hline $\mathbf{F}_{\mathbf{5}}$ & $2.96 \pm 0.030$ & $4.55 \pm 0.044$ & $0.465 \pm 0.025$ & $8.02 \pm 0.027$ & $4.012 \pm 0.036$ \\
\hline $\mathbf{F}_{\mathbf{6}}$ & $2.62 \pm 0.025$ & $4.63 \pm 0.036$ & $0.434 \pm 0.021$ & $8.18 \pm 0.030$ & $4.023 \pm 0.036$ \\
\hline
\end{tabular}

*mean of 3 readings

In vitro dissolution studies:

The results of in vitro Dissolution studies are shown in Table no. 8. The cumulative percentage of drug dissolution from F1 to F6 ranges from $52.69 \%$ to $85.54 \%$. Formulation ' $F 3$ ' shows second highest percentage drug release (84.6947) and from the graph it shows the drug release in 'Sustained release manner' compare to other formulations. The release kinetics was evaluated by making use of Zero order, First order, Higuchi's diffusion and Peppas equation.

The drug release through the Microsponge hydrogel of Parecoxib follows Peppas dissolution kinetics with sustained release mechanism and the ' $n$ ' values are in between 0.61 to 0.76 . By fitting in the KorsemeyerPeppas equation the release kinetics follows non Fickian kinetics, because the ' $n$ ' values are in between 0.5 to 1 , so the release is following non Fickian, dissolution kinetics. The ' $n$ ' values and $R^{2}$ values of all six Microsponge formulations are mentioned in Table no. 9.

Table 8: In- vitro dissolution studies of Microsponge sustained released tablets $F_{1}$ to $F_{6}$

\begin{tabular}{|c|c|c|c|c|c|c|}
\hline \multirow{3}{*}{$\begin{array}{l}\text { Time } \\
\text { (hr) }\end{array}$} & \multicolumn{6}{|c|}{ \% Drug Release * } \\
\hline & \multicolumn{6}{|l|}{$\overline{\mathrm{X}} \pm \mathrm{SD}$} \\
\hline & F1 & $\mathbf{F 2}$ & F3 & F4 & F5 & F6 \\
\hline 0 & 0 & 0 & 0 & 0 & 0 & 0 \\
\hline 0.5 & $3.25 \pm 0.036$ & $4.35 \pm 0.036$ & $3.62 \pm 0.040$ & $3.26 \pm 0.040$ & $2.36 \pm 0.036$ & $5.36 \pm 0.022$ \\
\hline 1 & $8.62 \pm 0.022$ & $6.04 \pm 0.036$ & $9.62 \pm 0.0360$ & $8.62 \pm 0.026$ & $8.63 \pm 0.027$ & $9.35 \pm 0.031$ \\
\hline 1.5 & $15.24 \pm 0.040$ & $19.25 \pm 0.040$ & $14.69 \pm 0.027$ & $15.24 \pm 0.036$ & $12.36 \pm 0.025$ & $16.23 \pm 0.027$ \\
\hline 2 & $22.95 \pm 0.036$ & $23.64 \pm 0.030$ & $25.96 \pm 0.036$ & $22.96 \pm 0.022$ & $16.69 \pm 0.036$ & $23.68 \pm 0.022$ \\
\hline 3 & $38.16 \pm 0.038$ & $40.24 \pm 0.036$ & $39.56 \pm 0.031$ & $38.18 \pm 0.040$ & $18.68 \pm 0.040$ & $30.76 \pm 0.040$ \\
\hline 4 & $52.84 \pm 0.040$ & $55.23 \pm 0.036$ & $52.31 \pm 0.028$ & $52.80 \pm 0.036$ & $22.64 \pm 0.031$ & $36.96 \pm 0.027$ \\
\hline 5 & $68.23 \pm 0.030$ & $63.25 \pm 0.040$ & $60.64 \pm 0.036$ & $68.24 \pm 0.028$ & $26.96 \pm 0.036$ & $45.68 \pm 0.031$ \\
\hline 6 & $80.64 \pm 0.036$ & $69.65 \pm 0.040$ & $70.69 \pm 0.040$ & $75.65 \pm 0.036$ & $40.64 \pm 0.040$ & $59.35 \pm 0.036$ \\
\hline 7 & $82.35 \pm 0.040$ & $76.25 \pm 0.027$ & $75.62 \pm 0.022$ & $82.36 \pm 0.031$ & $59.65 \pm 0.022$ & $60.56 \pm 0.036$ \\
\hline 8 & $83.36 \pm 0.036$ & $83.02 \pm 0.028$ & $81.65 \pm 0.030$ & $83.37 \pm 0.027$ & $66.56 \pm 0.036$ & $66.86 \pm 0.040$ \\
\hline 9 & $81.13 \pm 0.030$ & $84.56 \pm 0.036$ & $83.68 \pm 0.035$ & $81.13 \pm 0.040$ & $70.69 \pm 0.022$ & $75.63 \pm 0.022$ \\
\hline 10 & $80.22 \pm 0.025$ & $83.35 \pm 0.027$ & $82.96 \pm 0.031$ & $80.22 \pm 0.022$ & $80.65 \pm 0.040$ & $81.65 \pm 0.028$ \\
\hline 11 & $81.23 \pm 0.035$ & $84.64 \pm 0.036$ & $84.69 \pm 0.036$ & $78.36 \pm 0.036$ & $82.63 \pm 0.035$ & $78.62 \pm 0.040$ \\
\hline 12 & $82.34 \pm 0.036$ & $83.35 \pm 0.036$ & $81.26 \pm 0.027$ & $71.12 \pm 0.031$ & $76.35 \pm 0.031$ & $66.52 \pm 0.038$ \\
\hline 18 & $83.95 \pm 0.036$ & $80.63 \pm 0.031$ & $82.86 \pm 0.028$ & $63.25 \pm 0.040$ & $72.25 \pm 0.022$ & $60.65 \pm 0.027$ \\
\hline 24 & $85.54 \pm 0.031$ & $72.32 \pm 0.031$ & $76.56 \pm 0.036$ & $53.26 \pm 0.038$ & $52.69 \pm 0.028$ & $53.65 \pm 0.036$ \\
\hline
\end{tabular}


Maruthi. $\mathrm{N}$ et al., Journal of Biomedical and Pharmaceutical Research

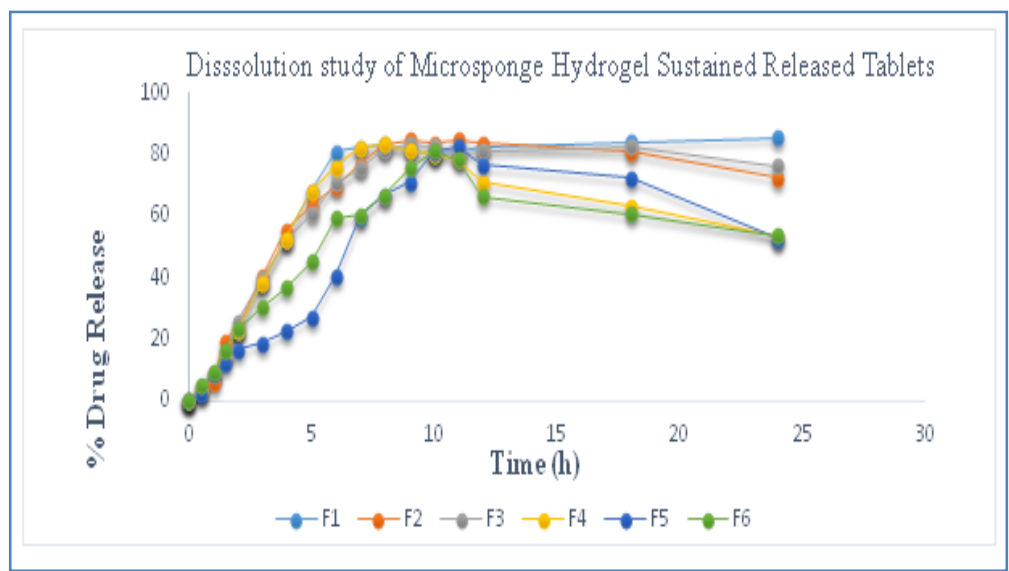

Figure 7: Graph of In-vitro dissolution study of Microsponge Hydrogel Sustained Released Tablet formulation $F_{1}$ to $F_{6}$

Table 9: Regression co-efficient $\left(R^{2}\right)$ values of Parecoxib Microsponge hydrogel Sustained Tablets according to different kinetic models

\begin{tabular}{|c|c|c|c|c|c|c|c|}
\hline \multirow[t]{2}{*}{ Formulation } & \multicolumn{2}{|c|}{ Zero order } & \multicolumn{2}{|c|}{ First order } & \multirow{2}{*}{$\begin{array}{l}\text { Higuchi } \\
\mathrm{R}^{2}\end{array}$} & \multicolumn{2}{|l|}{ Peppas } \\
\hline & $\mathbf{R}^{2}$ & $n$ & $\mathbf{R}^{2}$ & $n$ & & $\mathrm{R}^{2}$ & $\mathbf{n}$ \\
\hline $\mathrm{F}_{1}$ & 0.5517 & 3.5899 & 0.6345 & 0.090 & 0.7794 & 0.8203 & 0.7294 \\
\hline$F_{2}$ & 0.4063 & 2.5191 & 0.3220 & 0.046 & 0.6480 & 0.7826 & 0.6185 \\
\hline $\mathrm{F}_{3}$ & 0.4838 & 3.1453 & 0.4640 & 0.069 & 0.7318 & 0.7992 & 0.6745 \\
\hline $\mathrm{F}_{4}$ & 0.2739 & 2.3245 & 0.1839 & 0.042 & 0.5225 & 0.6765 & 0.6322 \\
\hline $\mathrm{F}_{5}$ & 0.5019 & 3.1632 & 0.4145 & 0.060 & 0.6830 & 0.8406 & 0.7693 \\
\hline $\mathrm{F}_{6}$ & 0.3937 & 2.865 & 0.3291 & 0.060 & 0.6497 & 0.7236 & 0.7027 \\
\hline
\end{tabular}

\section{Conclusion}

The present study was to formulate, and evaluate the Parecoxib loaded Microsponge hydrogel sustained released tablets. To achieve six formulations of Microsponges were prepared by quasi emulsion solvent diffusion method using Eudragit RS 100 and Ethyl cellulose as polymers. Prepared Microsponges were subjected for evaluation for Particle size analysis, Surface morphology, Differential Scanning Calorimetric analysis, Fourier Transform infrared spectroscopy analysis, pH studies, viscosity, Drug content studies and in vitro diffusion studies. And evaluated for pre formulation as well as post formulation studies for tablet punching are also performed.

The Microsponges formed have smooth surface and discrete spherical and highly porous in nature as observed in SEM. DSC studies shows the drug is amorphously distributed in formulations. And the FTIR shows the drug and polymers are compatible by incorporating the drug with Eudragit RS 100 and Ethyl cellulose, the same peaks related to
Parecoxib were seen with slight change in their peaks. The in vitro diffusion studies of Microsponge hydrogel shows shown maximum amount of drug release in controlled manner. The diffusion studies follows Peppas diffusion and non Fickian kinetics. In vitro dissolution studies of prepared Microsponge hydrogel sustained release tablets follows Peppas's dissolution kinetics with sustained release mechanism. And by fitting in KorsemeyerPeppa's equation it shows non Fickian kinetics.

\section{Acknowledgment}

Very thankful to Dr. Bharathi D R, Principal, SJM College of Pharmacy, Chitradurga, Dr. T.S Nagaraja Head of the Department Pharmaceutics, Dr. J. Timmasetty HOD and Professor Department of Pharmaceutics, Bapuji College of Pharmacy, Davanagere, Guide Smt. Lakshmi Radhika G, for providing the facilities of Library and literature source. Authors are thank full to MCOPS, and Mysore for providing the DSC and SEM data. 
Maruthi. N et al., Journal of Biomedical and Pharmaceutical Research

\section{Reference:}

1. Agarwal G, Agarwal S, Karar PK, Goyal S. Oral Sustained Release Tablets: An Oveview with a Special Emphesis on Matrix Tablet. Americal Journal of Advanced Drug Delivery. 2017; 5(2):64-76.

2. Shah $\mathrm{H}$, Patel K. Formulation and evaluation of controlled release colon targeted microsponge of Aceclofenac. The Pharma Innovation. 2014 Dec 1; 3(10, Part B):81.

3. Ghosh B Uppalapati Y Tadimarri VS Deshpande K. Formulation and Evaluation of Sitagliptin Microsponges Using Different Polymers. Int J Nano Rech. 2018; 1(2): 18-22.

4. Rekha U, Manjula BP. Formulation and evaluation of microsponges for topical drug delivery of mometasone furoate. International Journal of Pharmacy and Pharmaceutical Sciences. 2011; 3(4):133-7.

5. Ganesh $A$, Chandran $S M$, Aparna $P$, Jaghatha $T$ and Rajesh RS. Microsponge-A Novel Drug Delivery System: An Overview. Indo American Journal of Pharmaceutical Sciences. 2018 May 1; 5(5):4823-30.

6. Moin A, Deb TK, Osmani RA, Bhosale RR, Hani $U$. Fabrication, characterization, and evaluation of microsponge delivery system for facilitated fungal therapy. Journal of basic and clinical pharmacy. 2016 Mar; 7(2):39.

7. Krishnaiah, YS, Sathyanarayana V, Karthikeya RS. Penetration enhancing effect of methanol on the percutaneous absorption of Nicardipine hydrochloride form HPC gel through excised rat epidermis. Pharm Dev Technol. 2002; 7(9):305-316.
8. Pongpaibul $\mathrm{Y}$, Price JC, Whitworth $\mathrm{CW}$. Preparation and evaluation of controlled release indomethacin microspheres. Drug Development and Industrial Pharmacy. 1984 Jan 1; 10(10):1597-616.

9. Rabirandranath $P$, Chakraborty $M$, Rabindra $D$, Gupta BK. In-vitro In-vivo correlation (IVIVC) study of leflunomide loaded Microspheres. Int J Pharm Pharmaceut Sci. 2009; 1(1):165-170.

10. Costa P, Loba JMS. Modelling and comparison of dissolution profiles. Eur J Pharm Sci. 2001; 13:123-133.

11. Sahana B, Santra K, Basu S, Mukherjee B. Development of biodegradable polymer based tamoxifen citrate loaded nanoparticles and effect of some manufacturing process parameters on them: a physicochemical and in-vitro evaluation. Int J Nanomedicine. 2010 Sep; 5:621-630.

12. Abdul-Razzaq $A$, Mahmood HS. Formulation \& in-vitro evaluation of clarithromycin floating microsponge capsule. Karbala journal of pharmaceutical sciences. 2016(11):27-35.

13. Zheng ZC, Wang XY, Du XJ. Preparation and characterization of sustained release matrix tablets of Tizanidine hydrochloride for spinal injuries. Tropical Journal of Pharmaceutical Research. 2015; 14(10):1749-54.

14. D'Souza JI, More HN. Topical antiinflammatory gels of Fluocinolone Acetonide entrapped in Eudragit based microsponge delivery system. Research Journal of Pharmacy and Technology. 2008; 1(4):502-6.

15. Indian Pharmacopoeia. 2014. 